\title{
Elbow valgus stability of the transverse bundle of the ulnar collateral ligament
}

\author{
Mutsuaki Edama ${ }^{1 *} \mathbb{D}$, Kanta Matsuzawa ${ }^{1}$, Hirotake Yokota ${ }^{1}$, Ryo Hirabayashi ${ }^{1}$, Chie Sekine ${ }^{1}$, Sae Maruyama ${ }^{1}$ and \\ Noboru Sato ${ }^{2}$
}

\begin{abstract}
Background: The purpose of this study was to clarify elbow valgus stability of the transverse bundle (TB). We hypothesized that the transverse bundle is involved in elbow valgus stability.

Methods: Twelve elbows of six Japanese Thiel-embalmed cadavers were evaluated. The skin, subcutaneous tissue and origin of forearm flexors were removed from about $5 \mathrm{~cm}$ proximal to the elbow to about $5 \mathrm{~cm}$ distal to the elbow, and the ulnar collateral ligament was dissected (intact state). The cut state was defined as the state when the TB was cut in the middle. The joint space of the humeroulnar joint (JS) was measured in the intact state and then in the cut state. With the elbow flexed to $30^{\circ}$, elbow valgus stress was gradually increased to $30,60 \mathrm{~N}$ using the Telos Stress Device, and the JS was measured by ultrasonography under each load condition. Paired t-testing was performed to compare the JS between the intact and cut states under each load.
\end{abstract}

Results: No significant difference in JS was identified between the intact and cut state at start limb position. The JS was significantly higher in the cut state than in the intact state at both $30 \mathrm{~N}$ and $60 \mathrm{~N}$.

Conclusion: The findings from this study suggested that the TB may be involved in elbow valgus stability.

Keywords: Thiel-embalmed cadavers, Gross anatomy, Elbow joint, Ultrasonography

\section{Introduction}

There is currently insufficient evidence in the literature to establish statistically significant differences in the effects of conservative versus surgical treatment on the functional outcomes of patients with the ulnar collateral ligament (UCL) lesions [1]. Therefore, it is important to clarify the functional role of UCL.

The UCL consists of an anterior bundle $(\mathrm{AB})$, posterior bundle, and transverse bundle (TB) [2-4]. The AB has been reported as a primary stabilizer for elbow valgus stress, with the posterior bundle as a secondary stabilizer [5-9]. Many anatomical studies [3, 4, 7, 10-24] and

\footnotetext{
*Correspondence: edama@nuhw.ac.jp

${ }^{1}$ Institute for Human Movement and Medical Sciences, Niigata University

of Health and Welfare, Niigata, Shimami-cho 1398, Kita-ku, Niigata

City 950-3198, Japan

Full list of author information is available at the end of the article
}

biomechanical studies [25-30] have been reported on $\mathrm{AB}$ and $\mathrm{PB}$. But there are few anatomical studies and biomechanical studies on TB $[2,20,31,32]$. The TB has been thought to potentially assist function of the $A B$, as this bundle is continuous with the $\mathrm{AB}[2,20,31,32]$. On the other hand, the TB has not been thought to be involved in elbow valgus stability [10,33-35], because the bundle does not cross the humeroulnar joint [31]. Ciccotti et al. [36] performed a study that divided fresh cadavers into two groups, measuring the joint space of the humeroulnar joint (JS) using ultrasonography before and after cutting soft tissues [36]. As a result, one group showed significantly increased JS after cutting the TB, but no significant difference was seen in the other group. These suggested that the contribution of the TB to elbow valgus stability has not been sufficiently investigated. In addition, that study examining elbow valgus stability had not specifically focused on the $\mathrm{TB}$, and specimen conditions original author(s) and the source, provide a link to the Creative Commons licence, and indicate if changes were made. The images or other third party material in this article are included in the article's Creative Commons licence, unless indicated otherwise in a credit line to the material. If material is not included in the article's Creative Commons licence and your intended use is not permitted by statutory regulation or exceeds the permitted use, you will need to obtain permission directly from the copyright holder. To view a copy of this licence, visit http://creativecommons.org/licenses/by/4.0/. The Creative Commons Public Domain Dedication waiver (http://creativeco mmons.org/publicdomain/zero/1.0/) applies to the data made available in this article, unless otherwise stated in a credit line to the data. 
may differ due to the order in which soft tissues were cut in different groups [36]. Therefore, we believe that focusing on the TB is important, and evaluation and comparison under the same conditions is needed to clarify elbow valgus stability of the TB.

The purpose of this study was to clarify elbow valgus stability of the TB. We hypothesized that the TB is involved in elbow valgus stability.

\section{Methods \\ Cadavers}

Twelve elbows from six Japanese Thiel-embalmed cadavers (mean age at death, $87.8 \pm 5.8$ years; 4 males, 2 females) donated to the university anatomy program were evaluated. Thiel embalming has been reported as a fixation method that can maintain flexibility in a life-like condition [37, 38], facilitating reliable ultrasound imaging $[39,40]$ and life-like mechanical properties $[37,39,40]$. In addition, Thiel-embalmed cadavers reportedly show JS changes similar to those seen in living human volunteers when elbow valgus stress is applied [41]. Specimens with deformation of the elbow joint or a history or elbow surgery were excluded. This study was performed in accordance with the Declaration of Helsinki after all protocols were approved by the ethics committee of our institution.

\section{Measurement conditions}

For dissection, the skin and subcutaneous tissues were removed from about $5 \mathrm{~cm}$ proximal to the elbow to about $5 \mathrm{~cm}$ distal to the elbow. The origins of the pronator teres, flexor carpi radialis, flexor digitorum superficialis and flexor carpi ulnaris muscles were removed, and the UCL was dissected [32]. The ulnar nerve was cut, the anterior common tendon was not removed, but the posterior common tendon was removed (Fig. 1). The intact state was defined as the state in which the UCL had been dissected, while the cut state was defined as the state when the TB had been cut in the middle. The JS was measured in the intact state, and then in the cut state, with the interval between measurements set at $15 \mathrm{~min}$.

\section{Measurement of the joint space in the humeroulnar joint}

This study referred to a previous study [41] that measured the JS. Thiel-embalmed cadavers were placed in the supine position, with the shoulder abducted and in $90^{\circ}$ of external rotation, with the elbow flexed to $30^{\circ}$ and the forearm supinated in a Telos Stress Device (Telos) (Aimedic MMT, Tokyo, Japan). JS measurement was performed using ultrasonography (LOGIQ eV2; GE Healthcare, Qujing, China) with a $12-\mathrm{MHz}$ linear probe. The probe was placed on the medial side of the elbow joint, and $A B$ was visualized using the humeral trochlea and sublime tubercle of the ulna as landmarks (Fig. 2A). Using

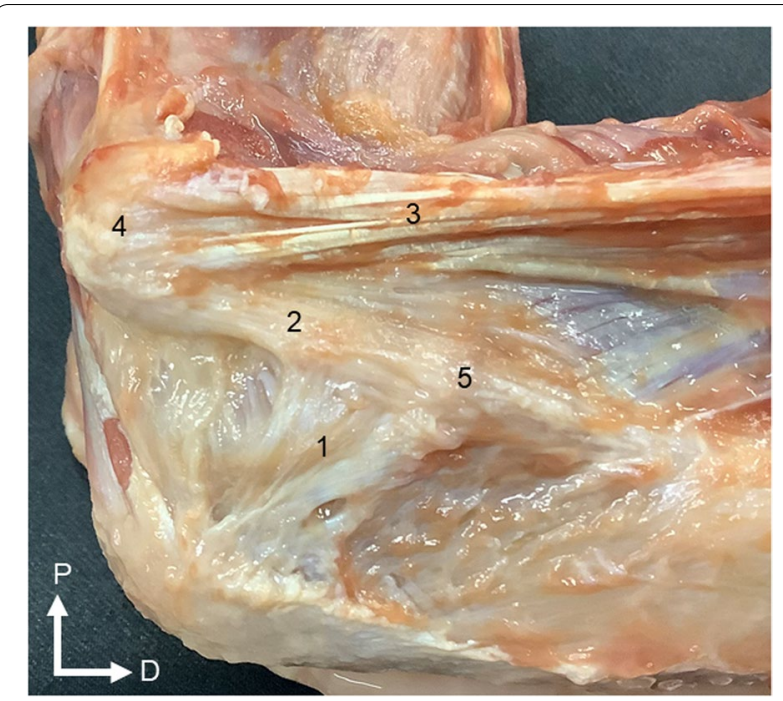

Fig. 1 Dissection of the transverse bundle of the ulnar collateral ligament (left elbow, medial view). 1: Transverse bundle of the ulnar collateral ligament; 2: anterior bundle of the ulnar collateral ligament; 3: anterior common tendon; 4: medial epicondyle of the humerus; 5 : sublime tubercle of the ulna. P: proximal; D: distal

the built-in calipers of the ultrasonography device, the JS was measured as the distance between the distal-medial corner of the humeral trochlea and the proximal edge of the sublime tubercle of the ulna (Fig. 2B). Sufficient the intraclass correlation coefficient (ICC) has been confirmed for the US measurement [41]. US measurement was performed by 1 operator (M.E.) and the Telos was performed by another operator (K.M.). This study also referred to a previous study [41] for the measurement protocol. The Telos was first set to starting limb position, and three images of the medial elbow were taken. The load was then gradually increased at $+10 \mathrm{~N} / \mathrm{s}$, and three ultrasonic images were taken within $10 \mathrm{~s}$ when $30 \mathrm{~N}$ was reached, and again when $60 \mathrm{~N}$ was reached. Mean values of the JS from the three images were used (Fig. 3).

\section{Statistical analysis}

To examine the elbow valgus stability of the TB, paired $\mathrm{t}$-testing was performed for the JS of the intact and cut states under each load. Differences were considered significant at the $5 \%$ level.

\section{Results}

No significant differences in JS were seen between intact and cut states at starting limb position. The IS was significantly higher in the cut state than in the intact state at both $30 \mathrm{~N}(P=0.044)$ and $60 \mathrm{~N}(P=0.004)$ (Table 1$)$. 


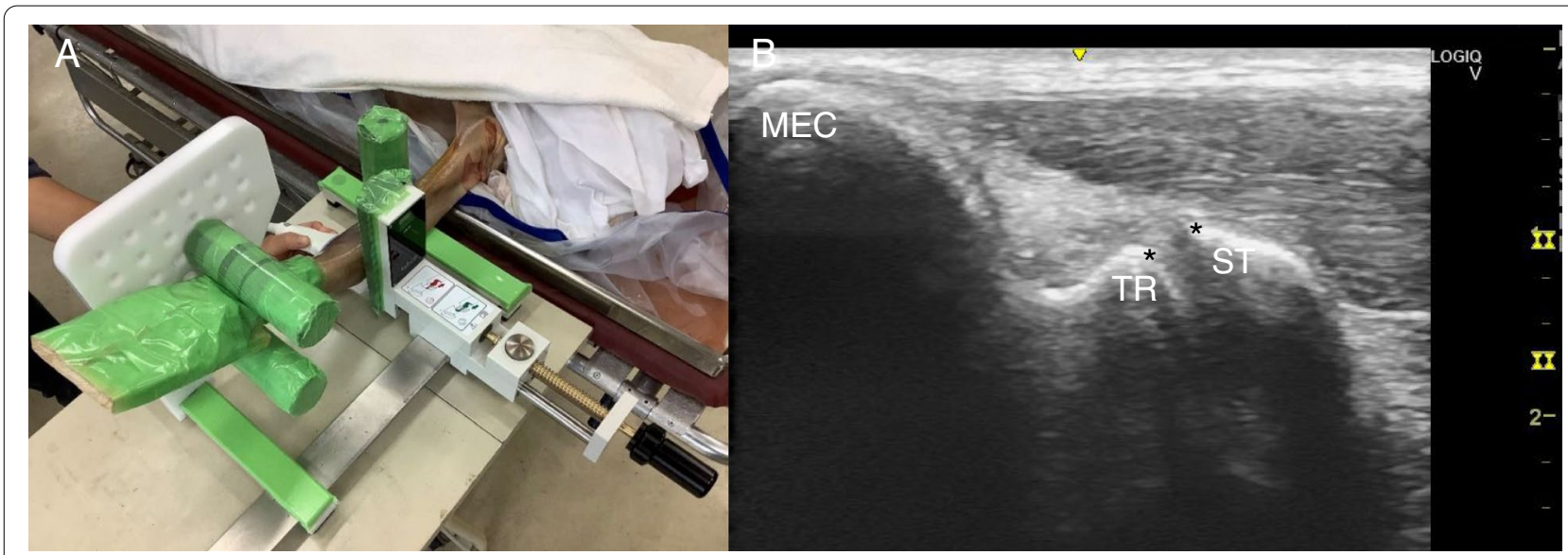

Fig. 2 Measurement position for ultrasonic imaging. A Measurement position of the Thiel cadaver. The Thiel cadaver is placed in the supine position with the shoulder in abduction and external rotation of $90^{\circ}$, and the elbow at $30^{\circ}$ of flexion and forearm supination in the Telos stress device. B Long-axis image of the humeroulnar joint. MEC: medial epicondyle of the humerus; TR: trochlea of the humerus; ST: sublime tubercle of the ulna

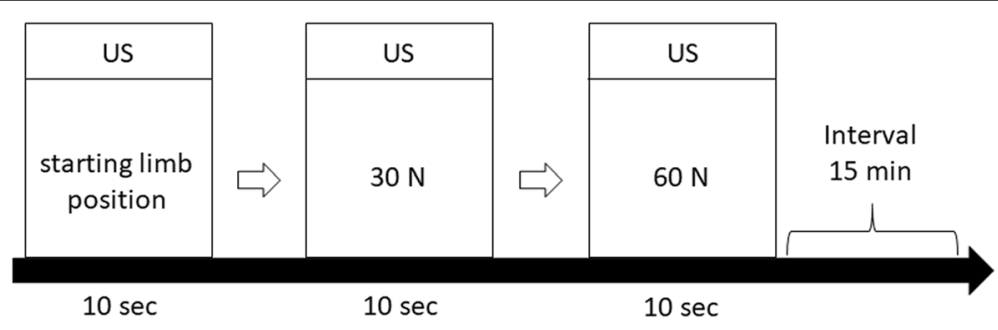

Fig. 3 Measurement protocol of the joint space of the humeroulnaris joint. First, the Telos device is set to starting limb position, and three images of the medial part of the elbow are taken. The load is then gradually increased at $10 \mathrm{~N} / \mathrm{sec}$, and when $30 \mathrm{~N}$ and $60 \mathrm{~N}$ are reached, three ultrasonic images are taken within $10 \mathrm{~s}$ at each point. US: Take three ultrasound images. White arrows: the load is gradually increased at $10 \mathrm{~N} / \mathrm{sec}$

Table 1 Joint space of the humeroulnar joint at each load volume

\begin{tabular}{lccc}
\hline & Intact state & Cut state & $P$ value \\
\hline $\begin{array}{l}\text { Starting limb } \\
\text { position }\end{array}$ & $4.03 \pm 0.69$ & $3.97 \pm 0.63$ & 0.238 \\
$30 \mathrm{~N}$ & $4.31 \pm 0.54$ & $4.41 \pm 0.65$ & 0.044 \\
$60 \mathrm{~N}$ & $4.62 \pm 0.59$ & $4.77 \pm 0.62$ & 0.004 \\
\hline
\end{tabular}

Values are expressed in millimeters as means \pm standard deviations Intact state: The ulnar collateral ligament was dissected

Cut state: The transverse bundle of the ulnar collateral ligament was cut in the middle

\section{Discussion}

This study focused on the TB and examined elbow valgus stability under different conditions of the TB using Thiel-embalmed cadavers. To the best of our knowledge, no previous studies have focused on the TB and examined elbow valgus stability of the TB.
In this study, no significant difference in JS size between intact and cut states was seen at starting limb position, but the JS was significantly larger in the cut state than in the intact state at both $30 \mathrm{~N}$ and $60 \mathrm{~N}$. This study therefore suggested that the TB may be involved in elbow valgus stability. A previous study reported that osseous, capsule, and the UCL are involved in elbow valgus stability [8]. Among these, the AB was reported to be the most involved in elbow valgus stability [7]. Previous studies have reported that the TB is continuous with the $\mathrm{AB}$ in all specimens $[2,20,32,35]$. The $\mathrm{TB}$ may thus be secondarily involved in elbow valgus stability. This study suggests that it may provide useful basic data for the diagnosis and reconstruction of UCL injury.

This study has several limitations. First, this study is that the TB could not be classified based on morphology because of the small number of specimens. In the previous studies, the TB was classified as follows TB does not continue the entire length of the $A B$ or $T B$ continues the entire length of the $A B$ [2, 32]. Further study of a larger number of specimens is thus needed, to 
examine whether the function of the TB differs depending on morphology. Second, it has been reported that the mechanical properties of Thiel cadaver are not similar to life-like, depending on the measurement part [42]. But, in a previous study, it was revealed that the changes in JS associated with increased elbow valgus stress are similar to those in human volunteers [41]. Third, this study is that the dominant hand of the donors was unknown, and whether donors had been involved in overhead sports during their lifetime was also unknown. A previous study reported that the difference in the JS between valgus stress and no valgus stress was significantly higher in the dominant arm than in the non-dominant arm [43]. A previous study also reported that the JS of professional pitchers was significantly greater in the dominant arm than in the non-dominant arm [44]. In the present study, the numbers of left and right samples were balanced as much as possible to minimize these effects. Therefore, the effects of the dominant arm and involvement in overhead sports were thought to have been minimized.

\section{Conclusions}

The findings of this study suggest that the TB may be involved in elbow valgus stability.

\section{Abbreviations \\ AB: anterior bundle; JS: humeroulnar joint; TB: transverse bundle; Telos: Telos Stress Device; UCL: ulnar collateral ligament.}

\section{Acknowledgements}

The authors would like to acknowledge and thank those anonymous individuals who generously donated their bodies so that this study could be performed, in addition to technical staff members Kenichi Soma and Kenjiro Ito for helping with cadaver management. This study was supported by a Grant-in-Aid for Scientific Research (19K11358) from the Japanese Society for the Promotion of Science (JSPS).

\section{Authors' contributions}

ME and KM contributed to the study design and data collection, and drafted the manuscript; $\mathrm{HY}, \mathrm{RH}$ contributed to the data analysis and made critical revisions to the manuscript; CS, SM made critical revisions to the manuscript; NS supervised the study, contributed to the analysis and interpretation of data, and made critical revisions to the manuscript. All authors read and approved the final manuscript prior to submission.

\section{Funding}

None.

\section{Availability of data and materials}

The datasets generated and/or analysed during the current study are not publicly available due to limitations of ethical approval involving the patient data and anonymity but are available from the corresponding author on reasonable request.

\section{Declarations}

\section{Consent to participate}

Not Applicable.

\section{Ethics approval}

All methods were carried out in accordance with the 1964 Declaration of Helsinki, and all cadavers were legally donated for research purposes to the Niigata University Graduate School of Medical and Dental Sciences at Niigata, Japan. This study was approved by the ethics committee of the Niigata University Graduate School of Medical and Dental Sciences. Informed consent was obtained from the families of all subjects.

\section{Competing interests}

The authors declare that they have no competing interests.

\section{Author details}

${ }^{1}$ Institute for Human Movement and Medical Sciences, Niigata University of Health and Welfare, Niigata, Shimami-cho 1398, Kita-ku, Niigata City 950-3198, Japan. ${ }^{2}$ Division of Gross Anatomy and Morphogenesis, Niigata University Graduate School of Medical and Dental Sciences, Niigata, Japan.

Received: 8 June 2021 Accepted: 5 October 2021

Published online: 12 October 2021

\section{References}

1. Biz C, Crimì A, Belluzzi E, Maschio N, Baracco R, Volpin A, et al. Conservative versus surgical Management of Elbow Medial Ulnar Collateral Ligament Injury: a systematic review. Orthop Surg. 2019;11(6):974-84.

2. Kimata K, Yasui M, Yokota H, Hirai S, Naito M, Nakano T. Transverse ligament of the elbow joint: an anatomic study of cadavers. J Shoulder Elb Surg. 2019;28(11):2253-8

3. Ikezu M, Edama M, Matsuzawa K, Kaneko F, Shimizu S, Hirabayashi R, et al. Morphological features of the ulnar collateral ligament of the elbow and common tendon of flexor-pronator muscles. Orthop J Sports Med. 2020;8(9):2325967120952415.

4. Shimizu S, Edama M, Ikezu M, Matsuzawa K, Kaneko F, Kageyama I. Morphological features of the posterior oblique ligament of the ulnar collateral ligament of the elbow joint. Surg Radiol Anat. 2020;42(3):243-8.

5. Campbell DG, Menz A, Isaacs J. Dynamic ankle ultrasonography. A new imaging technique for acute ankle ligament injuries. Am J Sports Med. 1994:22(6):855-8.

6. Callaway GH, Field LD, Deng XH, Torzilli PA, O'Brien SJ, Altchek DW, et al. Biomechanical evaluation of the medial collateral ligament of the elbow. J Bone Joint Surg Am. 1997;79(8):1223-31.

7. Floris S, Olsen BS, Dalstra M, Sojbjerg JO, Sneppen O. The medial collateral ligament of the elbow joint: anatomy and kinematics. J Shoulder Elb Surg. 1998;7(4):345-51.

8. Morrey BF, An KN. Articular and ligamentous contributions to the stability of the elbow joint. Am J Sports Med. 1983;11(5):315-9.

9. Hotchkiss RN, Weiland AJ. Valgus stability of the elbow. J Orthop Res. 1987;5(3):372-7.

10. Morrey BF, An KN. Functional anatomy of the ligaments of the elbow. Clin Orthop Relat Res. 1985:201:84-90.

11. Regan WD, Korinek SL, Morrey BF, An KN. Biomechanical study of ligaments around the elbow joint. Clin Orthop Relat Res. 1991;271:170-9.

12. Timmerman LA, Andrews JR. Histology and arthroscopic anatomy of the ulnar collateral ligament of the elbow. Am J Sports Med. 1994;22(5):667-73.

13. Cage DJ, Abrams RA, Callahan JJ, Botte MJ. Soft tissue attachments of the ulnar coronoid process. An anatomic study with radiographic correlation. Clin Orthop Relat Res. 1995;320:154-8.

14. Beckett KS, McConnell P, Lagopoulos M, Newman RJ. Variations in the normal anatomy of the collateral ligaments of the human elbow joint. J Anat. 2000;197(Pt 3):507-11.

15. Eygendaal D, Valstar ER, Söjbjerg JO, Rozing PM. Biomechanical evaluation of the elbow using roentgen stereophotogrammetric analysis. Clin Orthop Relat Res. 2002;396:100-5.

16. Gurbuz H, Kutoglu T, Mesut R, Gurbuz H. Anatomical dimensions of anterior bundle of ulnar collateral ligament and its role in elbow stability. Folia Med (Plovdiv). 2005;47(1):47-52.

17. Safran MR, McGarry MH, Shin S, Han S, Lee TQ. Effects of elbow flexion and forearm rotation on valgus laxity of the elbow. J Bone Joint Surg Am. 2005;87(9):2065-74. 
18. Dugas JR, Ostrander RV, Cain EL, Kingsley D, Andrews JR. Anatomy of the anterior bundle of the ulnar collateral ligament. J Shoulder Elb Surg. 2007;16(5):657-60.

19. Frangiamore SJ, Moatshe G, Kruckeberg BM, Civitarese DM, Muckenhirn KJ, Chahla J, et al. Qualitative and quantitative analyses of the dynamic and static stabilizers of the medial elbow: An anatomic study. Am J Sports Med. 2018;46(3):687-94

20. Camp CL, Jahandar H, Sinatro AM, Imhauser CW, Altchek DW, Dines JS. Quantitative anatomic analysis of the medial ulnar collateral ligament complex of the elbow. Orthop J Sports Med. 2018;6(3):2325967118762751.

21. Dutton PH, Banffy MB, Nelson TJ, Metzger MF. Anatomic and biomechanical evaluation of ulnar tunnel position in medial ulnar collateral ligament reconstruction. Am J Sports Med. 2019;47(14):3491-7.

22. Otoshi K, Kikuchi S, Shishido H, Konno S. The proximal origins of the flexor-pronator muscles and their role in the dynamic stabilization of the elbow joint: an anatomical study. Surg Radiologic Anatomy. 2014;36(3):289-94.

23. Farrow LD, Mahoney AP, Sheppard JE, Schickendantz MS, Taljanovic MS. Sonographic assessment of the medial ulnar collateral ligament distal ulnar attachment. J Ultrasound Med. 2014;33(8):1485-90.

24. Farrow LD, Mahoney AJ, Stefancin JJ, Taljanovic MS, Sheppard JE, Schickendantz MS. Quantitative analysis of the medial ulnar collateral ligament ulnar footprint and its relationship to the ulnar sublime tubercle. Am J Sports Med. 2011;39(9):1936-41.

25. Buford WL Jr, Snijders JW, Patel W, Curry CM, Smith BA. Specimen specific, $3 \mathrm{D}$ modeling of the elbow-prediction of strain in the medial collateral ligament. Annu Int Conf IEEE Eng Med Biol Soc. 2012;2012:3348-51.

26. Ciccotti MG, Siegler S, Kuri JA 2nd, Thinnes JH. Murphy DJt: comparison of the biomechanical profile of the intact ulnar collateral ligament with the modified Jobe and the docking reconstructed elbow: an in vitro study. Am J Sports Med. 2009;37(5):974-81.

27. Cohen SB, Woods DP, Siegler S, Dodson CC, Namani R, Ciccotti MG. Biomechanical comparison of graft fixation at $30^{\circ}$ and $90^{\circ}$ of elbow flexion for ulnar collateral ligament reconstruction by the docking technique. J Shoulder Elb Surg. 2015;24(2):265-72.

28. Jackson TJ, Jarrell SE, Adamson GJ, Chung KC, Lee TQ. Biomechanical differences of the anterior and posterior bands of the ulnar collateral ligament of the elbow. Knee Surg Sports Traumatol Arthrosc. 2016;24(7):2319-23

29. Molenaars RJ, van den Bekerom MPJ, Eygendaal D, Oh LS. The pathoanatomy of the anterior bundle of the medial ulnar collateral ligament. Shoulder Elb Surg. 2019;28(8):1497-504.

30. Wavreille G, Seraphin J, Chantelot C, Marchandise X, Fontaine C. Ligament fibre recruitment of the elbow joint during gravity-loaded passive motion: an experimental study. Clin Biomech (Bristol, Avon). 2008;23(2):193-202.
31. Berg EE, DeHoll D. Radiography of the medial elbow ligaments. J Shoulder Elb Surg. 1997;6(6):528-33.

32. Matsuzawa K, Edama M, Otsuki T, Maruyama S, Ikezu M, Kageyama I. Relationship between morphology of transverse bundle of ulnar collateral ligament and adjacent tissues. Surg Radiol Anat. 2021;43(10):1603-7.

33. King GJW, Morrey BF, An K-N. Stabilizers of the elbow. J Shoulder Elb Surg. 1993:2(3):165-74.

34. Sojbjerg JO, Ovesen J, Nielsen S. Experimental elbow instability after transection of the medial collateral ligament. Clin Orthop Relat Res. 1987;218:186-90

35. Matsuzawa K, Edama M, Ikezu M, Kaneko F, Hirabayashi R, Kageyama I. The origin structure of each finger in the flexor digitorum superficialis muscle. Surg Radiol Anat. 2021:43(1):3-10.

36. Ciccotti MC, Hammoud S, Dodson CC, Cohen SB, Nazarian LN, Ciccotti MG. Stress ultrasound evaluation of medial elbow instability in a cadaveric model. Am J Sports Med. 2014;42(10):2463-9.

37. Liao X, Kemp S, Corner G, Eisma R, Huang Z. Elastic properties of Thiel-embalmed human ankle tendon and ligament. Clin Anatomy. 2015;28(7):917-24.

38. Healy SE, Rai BP, Biyani CS, Eisma R, Soames RW, Nabi G. Thiel embalming method for cadaver preservation: a review of new training model for urologic skills training. Urology. 2015;85(3):499-504.

39. Joy J, McLeod G, Lee N, Munirama S, Corner G, Eisma R, et al. Quantitative assessment of Thiel soft-embalmed human cadavers using shear wave elastography. Ann Anatomy - Anatomischer Anzeiger. 2015;202:52-6.

40. Munirama S, Zealley K, Schwab A, Columb M, Corner GA, Eisma R, et al. Trainee anaesthetist diagnosis of intraneural injection-a study comparing $\mathrm{B}$-mode ultrasound with the fusion of B-mode and elastography in the soft embalmed Thiel cadaver model. Br J Anaesth. 2016;117(6):792-800.

41. Matsuzawa K, Izawa S, Kato A, Fukaya K, Matsumoto K, Okura T, et al. Low signal intensities of MRIT1 mapping predict refractory diplopia in Graves' ophthalmopathy. Clin Endocrinol. 2020;92(6):536-44.

42. Fessel G, Frey K, Schweizer A, Calcagni M, Ullrich O, Snedeker JG. Suitability of Thiel embalmed tendons for biomechanical investigation. Ann Anat. 2011;193(3):237-41.

43. Singh $\mathrm{H}$, Osbahr DC, Wickham MQ, Kirkendall DT, Speer KP. Valgus laxity of the ulnar collateral ligament of the elbow in collegiate athletes. Am J Sports Med. 2001;29(5):558-61.

44. Ciccotti MG, Atanda A Jr, Nazarian LN, Dodson CC, Holmes L, Cohen SB. Stress sonography of the ulnar collateral ligament of the elbow in professional baseball pitchers: a 10-year study. Am J Sports Med. 2014;42(3):544-51.

\section{Publisher's Note}

Springer Nature remains neutral with regard to jurisdictional claims in published maps and institutional affiliations.
Ready to submit your research? Choose BMC and benefit from:

- fast, convenient online submission

- thorough peer review by experienced researchers in your field

- rapid publication on acceptance

- support for research data, including large and complex data types

- gold Open Access which fosters wider collaboration and increased citations

- maximum visibility for your research: over 100M website views per year

At BMC, research is always in progress.

Learn more biomedcentral.com/submissions 